Check for updates

Cite this: RSC Adv., 2019, 9, 23254

\title{
Controlling the nucleophilic properties of cobalt salen complexes for carbon dioxide capture $\uparrow$
}

\begin{abstract}
Meliton R. Chiong, III (D) *ab and Francis N. C. Paraan (D)
The nucleophilic properties of cobalt salen complexes are examined using density functional theory to investigate its carbon fixing capacity. In particular, carbon dioxide attack on neutral and anionic cobalt salen molecules is considered. Carbon fixation occurs for the anionic cobalt salen complex and is due to the nucleophilic interaction between the cobalt center and carbon dioxide molecule in a $\mathrm{Co} \mathrm{d}_{z^{2}}-\mathrm{CO}_{2} \pi^{*}$ interaction. A minimum energy path search by a nudged elastic band calculation reveals a lower forward activation energy for the anionic complex than the neutral complex, indicating that the formation of the anionic complex is thermodynamically and kinetically favored. In this case, the $\mathrm{CO}_{2}$ molecule is chemisorbed as partial charge transfer from the cobalt center to carbon dioxide is observed. Proposed reaction mechanisms explain how the $\mathrm{Co}-\mathrm{C}$ bond energy of the $\mathrm{CO}_{2}$-cobalt salen complex can be tuned by appropriate substitutions of electron donating or withdrawing groups on the phenyl ring.
\end{abstract}

Received 15th March 2019

Accepted 18th July 2019

DOI: 10.1039/c9ra01990a

rsc.li/rsc-advances

includes a description of hapticity, the number of contiguous atoms coordinated to the metal by the ligand, indicated by $\eta^{n}$, where $n$ is the number of atoms involved in a coordination bond.

Metal centers that have coordination vacancy or ligands that are good leaving groups are capable of forming a complex with the weakly electrophilic $\mathrm{CO}_{2}$, as illustrated in Fig. 1. In $\eta^{1}-\mathrm{CO}_{2}$ complex, the metal center forms a bond with $\mathrm{CO}_{2}$ through carbon directly. ${ }^{9}$ This bonding is characterized by the overlap of orbitals of an electron-rich metal center and a ligand that has the same symmetry label, forming a $\sigma$-bond. In $\eta^{2}-\mathrm{CO}_{2}$ complex, both carbon and oxygen atoms of $\mathrm{CO}_{2}$ form a bond with the metal center. This is characterized by a $\pi$-type interaction of the metal and ligand.

Common organic ligands that are used as catalysts include phthalocyanine, porphyrin, and cyclam. ${ }^{10-12}$ These tetradentate ligands offer possible binding sites in the axial positions as they form square planar metal complexes. Cobalt porphyrin complex was reported as a possible electrocatalyst in the reduction of $\mathrm{CO}_{2}$ to methane. ${ }^{13}$ Density functional theory (DFT) and ab initio molecular dynamics studies reported that the electrocatalytic reduction of $\mathrm{CO}_{2}$ to $\mathrm{CO}$ by cobalt porphyrin proceeds via intermediates in catalytic processes. Although initially identified as a poor ligand, $\mathrm{CO}_{2}$ has demonstrated outstanding versatility by exhibiting various coordination modes. Different coordination compounds formed by $\mathrm{CO}_{2}$ has been synthesized in recent years. ${ }^{7,8}$ The nomenclature of these compounds

${ }^{a}$ Materials Science and Engineering Program, University of the Philippines Diliman, Quezon City, Philippines. E-mail: mrchiong@msep.upd.edu.ph

${ }^{b}$ National Institute of Physics, University of the Philippines Diliman, Quezon City, Philippines

$\dagger$ Electronic supplementary information (ESI) available. See DOI: 10.1039/c9ra01990a

(a) $\eta^{1}-\mathrm{CO}_{2}$ complex

(b) $\eta^{2}-\mathrm{CO}_{2}$ complex
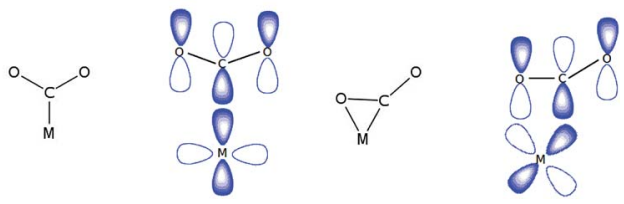

Fig. 1 (a) $\eta^{1}$ and (b) $\eta^{2}$ bonding scheme of $\mathrm{M}-\mathrm{CO}_{2}$ complexes. 


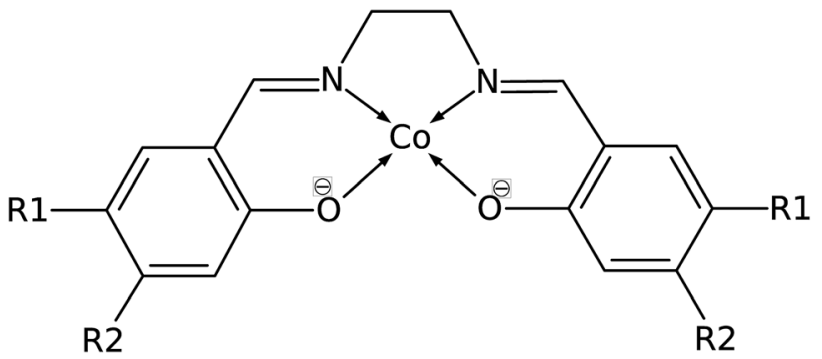

Fig. 2 Structure of Co(salen) $(\mathrm{R} 1=\mathrm{R} 2=\mathrm{H})$, salen $=N, N^{\prime}$-bis(salicylaldehyde)-ethylenediimino ligand. R1 and R2 are sites for substitution.

a $\mathrm{Co}$ (porphyrin)-COOH intermediate. ${ }^{\mathbf{1 4 , 1 5}}$ However, the use of a tetradentate Schiff-base ligand as an electrocatalyst has not been extensively studied. Schiff-base ligands such as $N, N^{\prime}$ bis(salicylaldehyde)-ethylenediimino ligand, abbreviated as salen, are coordinated to the metal center by phenolate oxygen and imine nitrogen which extend the conjugation of the phenyl ring. Fig. 2 shows the structure of cobalt salen complex. A study by Gambarotta et al. investigated the carbon capture behavior of a bifunctional salen ligand complex containing $\mathrm{Co}(\mathrm{I})$ and an alkali cation. ${ }^{16}$ It was recently demonstrated experimentally that $\mathrm{Ni}(\mathrm{II})$ (salen) and $\mathrm{Cu}$ (II)(salen) complexes can act as very efficient electrocatalysts for the electrocatalytic reduction of $\mathrm{CO}_{2} \cdot{ }^{17}$

The possibility of $\mathrm{Co}$ (salen) as an electrocatalyst can be examined because it is a square-planar complex with axial sites available for carbon fixation, and because it contains aromatic rings that can be exploited to control the electron density of the complex. Aromatic substitution with electron withdrawing or donating groups can affect the electron density and reactivity of the metal center. Thus, the substitution may provide an effective way to tune the affinity of carbon capture of organometallic complexes in electrocatalysis.

In this study, a theoretical investigation of the binding of carbon dioxide to cobalt salen complex, Co(salen), is examined using density functional theory (DFT). This paper is organized as follows. In Section 2 we present theoretical and computation details of our work. In Section 3, we report a stable structure formed by $\mathrm{CO}_{2}$ and the anionic $[\mathrm{Co}(\text { salen })]^{-}$. In Section 4 we further examined the binding process by analyzing the electronic structure of the complex and the orbital overlap of $\mathrm{CO}_{2}$ and Co. In Section 5, we discuss how the bond energy is manipulated by substituting electron donating or withdrawing groups on the ligand. Finally, we summarize our findings in Section 6 .

\section{Computational details}

DFT calculations were done using the generalized gradient approximation (GGA) with the Perdew-Burke-Ernzerhof (PBE) exchange-correlation functional. ${ }^{18}$ We used a plane-wave basis set and the pseudopotential method with ultrasoft pseudopotentials to obtain fairly accurate structural results at a lower computational cost. ${ }^{19-21}$ To ensure the completeness of this basis, the kinetic energy cutoff was set to $45 \mathrm{Ry}$ (450 Ry for the charge density cutoff) in which the variation in the total energy of the self-consistent field calculation was below $0.001 \mathrm{eV}$.
The bound $\mathrm{CO}_{2}$ and $\mathrm{Co}($ salen) system was modeled by indicating the position of the $\mathrm{CO}_{2}$ molecule where the $\mathrm{C}$ atom is on top of the Co atom so that the complex is characterized by a $\eta^{1}-\mathrm{C}$ coordination. We considered both neutral Co(salen) and anionic [Co(salen)] complexes, as well as their $\mathrm{CO}_{2}$-bound forms. Geometry optimization of these structures was done by fully optimizing all structural parameters until the forces on each atom is below $0.001 \mathrm{Ry}^{-1}$. For a charged system, Makov-Payne correction was employed in order to achieve faster convergence. ${ }^{22}$ The size of the simulation box was set to $30 \times 30 \times 30$ bohr $^{3}$ to ensure enough vacuum space between mirror images. This was done by increasing the dimensions of the cubic box until the variation in the total energy is less than 0.01 Ry. Brillouin zone sampling was performed at the $\Gamma$-point and treated with Gaussian smearing using a smearing parameter of $0.01 \mathrm{Ry}$.

Nudged elastic band calculation was done with climbing image scheme to search the minimum energy path and transition state structure of the formation of $\mathrm{Co}($ salen $)-\mathrm{CO}_{2}$ and $\left[\mathrm{Co}(\text { salen })-\mathrm{CO}_{2}\right]^{-}$adducts. ${ }^{23}$ The transition state image maximizes its energy along the band (reaction coordinate) and minimizes in all other directions. The activation energy of an elementary step can be obtained from the first-order saddle point of the potential energy surfaces, which corresponds to the highest energy along the minimum energy path.

The charge transfer between $\mathrm{CO}_{2}$ and the complex is characterized by the charge density difference defined as

$$
\Delta n(r)=n_{\mathrm{CO}_{2} / \mathrm{Co}(\text { salen })}(r)-\left[n_{\mathrm{CO}_{2}}(r)+n_{\mathrm{Co}(\text { salen })}(r)\right]
$$

where $n_{\mathrm{CO}_{2} / \mathrm{Co} \text { (salen) }}(r), n_{\mathrm{CO}_{2}}(r)$, and $n_{\mathrm{Co} \text { (salen) }}(r)$ are the electron charge density distributions of the $\mathrm{CO}_{2}$-complex adduct, $\mathrm{CO}_{2}$, and bare cobalt salen complex, respectively.

The bond energy is calculated using

$$
E_{\text {bond }}=E_{\mathrm{Co}(\text { salen })-\mathrm{CO}_{2}}-E_{\mathrm{Co}(\text { salen })}-E_{\mathrm{CO}_{2}}
$$

where $E_{\mathrm{Co}(\text { salen)-CO}}$ is the DFT energy of $\mathrm{Co}\left(\right.$ salen) $-\mathrm{CO}_{2}$.

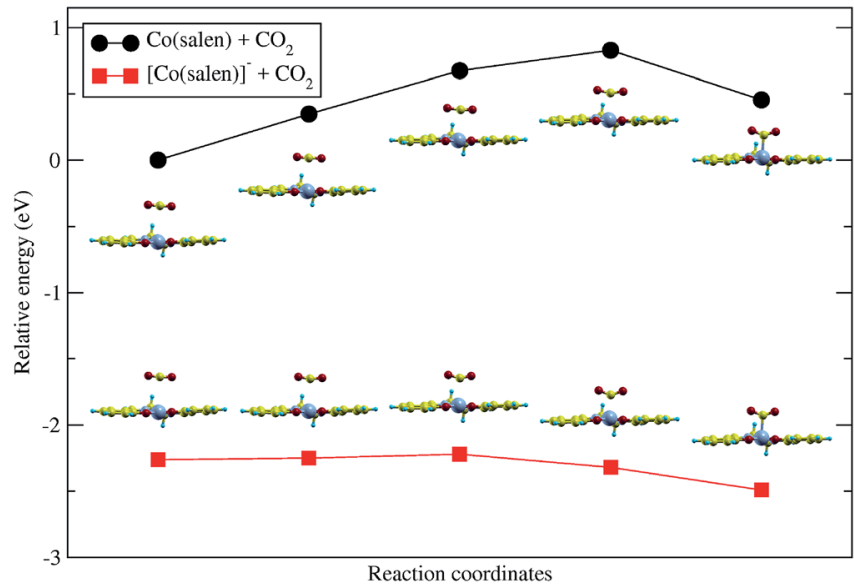

Fig. 3 Nudged elastic band calculation shows that the formation of (top) neutral $\mathrm{Co}\left(\right.$ salen) $-\mathrm{CO}_{2}$ complex is unfavored. The forward activation energy for this reaction is $0.828 \mathrm{eV}$. The formation of (bottom) [Co(salen) $\left.-\mathrm{CO}_{2}\right]^{-}$is favored with a forward activation energy of $0.042 \mathrm{eV}$. 


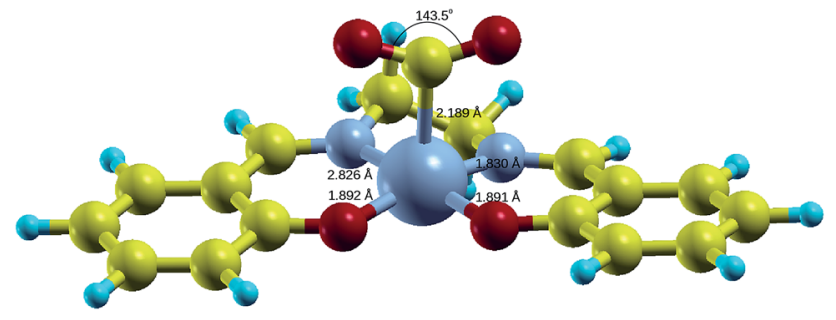

Fig. 4 Relaxed structure of $\left[\mathrm{Co}\left(\text { salen) }-\mathrm{CO}_{2}\right]^{-}\right.$complex. Yellow $=\mathrm{C}$, cyan $=\mathrm{H}$, red $=\mathrm{O}$, small gray $=\mathrm{N}$, big gray $=\mathrm{Co}$.

The calculations were performed using the pwSCF package of Quantum ESPRESSO, ${ }^{24}$ while postprocessing and visualization were done with the XCrySDen package. ${ }^{25}$

\section{Structural properties}

Upon relaxation of the $\mathrm{Co}($ salen $)-\mathrm{CO}_{2}$ structure, the $\mathrm{CO}_{2}$ molecule was unable to form a stable bond with the neutral Co(salen) complex. Any attempt to optimize the geometry of the different $\mathrm{Co}-\mathrm{CO}_{2}$ coordination modes, including $\eta^{1}(\mathrm{C}), \eta^{1}(\mathrm{O})$, and $\eta^{2}(\mathrm{C}, \mathrm{O})$, resulted in separate $\mathrm{Co}($ salen $)$ and $\mathrm{CO}_{2}$ molecules. On the other hand, the $\mathrm{CO}_{2}$ molecule was able to form a stable bond with the anionic $[\mathrm{Co}(\text { salen })]^{-}$complex. The equilibrium Co-C distance of the $\left[\mathrm{Co}(\text { salen })-\mathrm{CO}_{2}\right]^{-}$adduct is $2.189 \AA$ (Fig. 4).

A climbing-image nudged elastic band (CI-NEB) calculation with five images was done, where the initial and final images were fixed corresponding to the unbound and bound adducts, respectively. In the formation of the hypothetical, neutral $\mathrm{Co}$ (salen) $-\mathrm{CO}_{2}$ adduct, the initial image was chosen to correspond to the unbound $\mathrm{Co}(\mathrm{sa}-$ len) and $\mathrm{CO}_{2}$ molecules resulting from the geometry relaxation. Since a stable $\mathrm{Co}\left(\right.$ salen) $-\mathrm{CO}_{2}$ was not attained, the final image was chosen to have its atomic coordinates identical to those of the relaxed $\left[\mathrm{Co}(\text { salen })-\mathrm{CO}_{2}\right]^{-}$adduct, and its total charge adjusted to zero. In the formation of the anionic $\left[\mathrm{Co}(\text { salen })-\mathrm{CO}_{2}\right]^{-}$adduct, the initial and final images were chosen by relaxing both unbound and bound molecules, respectively.

As shown in Fig. 3, the energy of the bound $\mathrm{Co}\left(\right.$ salen) $-\mathrm{CO}_{2}$ adduct is relatively higher than the unbound state, signifying that the unbound state is more stable than the bound state. Moreover, the CI-NEB calculation shows an activation energy barrier of $0.828 \mathrm{eV}$ associated with the formation of bound $\mathrm{Co}$ (salen) $-\mathrm{CO}_{2}$, while the formation of $\left[\mathrm{Co}(\text { salen })-\mathrm{CO}_{2}\right]^{-}$from its unbound structures proceeds with a lower activation energy barrier of $0.042 \mathrm{eV}$. Furthermore, the energy of the bound $\left[\mathrm{Co}(\text { salen })-\mathrm{CO}_{2}\right]^{-}$is relatively lower than its unbound structures. Therefore, the formation of the anionic $\left[\mathrm{Co}(\text { salen })-\mathrm{CO}_{2}\right]^{-}$ adduct is both thermodynamically and kinetically favorable.

Fig. 4 shows the DFT-optimized structure of [Co(salen) $\left.-\mathrm{CO}_{2}\right]^{-}$ complex. The structural parameters are listed in Table 1. Both $\mathrm{C}-\mathrm{O}$ bond lengths of the bent $\mathrm{CO}_{2}$ are $1.217 \AA$ and $\mathrm{O}-\mathrm{C}-\mathrm{O}$ bond angle is $143.5^{\circ}$. In this case, a $\eta^{1}(\mathrm{C})-\mathrm{CO}_{2}$ complex is formed due to the formation of Co-C $\sigma$ bond. The closest available structural data is obtained from $\mathrm{Co}(\mathrm{n}-\mathrm{Pr}-\mathrm{salen})\left(\mathrm{CO}_{2}\right) \mathrm{K}(\mathrm{THP})$ where $\mathrm{O}-\mathrm{C}-\mathrm{O}$ bond angle is $132.0-134.9^{\circ}, \mathrm{C}-\mathrm{O}$ bond lengths of 1.20-1.24 $\AA$, and $\mathrm{Co}-\mathrm{C}$ bond length of 1.99-2.00 $\AA^{16}$ The deviation of the calculated values from experiment may be due to the additional stabilization by $\mathrm{K}^{+}$ cation as it acts as a Lewis base by coordinating with the oxygen atom of the $\mathrm{CO}_{2}$ molecule. The transition state structure for the formation of $\left[\mathrm{Co}(\text { salen })-\mathrm{CO}_{2}\right]^{-}$adduct is shown in Fig. $\mathrm{S} 1$ in the ESI, $\dagger$ with a Co-C bond length of $2.666 \AA$ and $\mathrm{O}-\mathrm{C}-\mathrm{O}$ bond angle of $154.7^{\circ}$, as the $\mathrm{CO}_{2}$ molecule slowly approaches the Co atom and the $\mathrm{O}-\mathrm{C}-\mathrm{O}$ bond slowly bends.

Bader charge analysis was performed in order to measure the partial charge associated with each atom. ${ }^{26}$ During the binding process, partial charges were redistributed from the Co atom to the $\mathrm{CO}_{2}$ molecule, as the partial charge on Co increased while that of $\mathrm{CO}_{2}$ decreased. Charge transfer was also visualized in the charge density difference plot of the $\mathrm{Co}-\mathrm{CO}_{2}$ plane as shown in Fig. 5. There was an increased accumulation of charge in the region between carbon and cobalt (red region), indicating an enhanced chemical bonding. The charges were redistributed from blue to red regions, showing a depleted electron density associated with cobalt, and increased electron density associated with carbon dioxide. Furthermore, the loss of linearity of $\mathrm{CO}_{2}$ is associated with the formation of the $\mathrm{CO}_{2}{ }^{-}$radical anion as the metal center is oxidized from $\mathrm{Co}(\mathrm{I})$ to $\mathrm{Co}(\mathrm{II})$ accompanying the charge transfer. The stabilization of the complex resembles a metal-to-ligand charge transfer occurring in the nucleophilic attack of Co to the electrophilic carbon. ${ }^{27-29}$

\section{Electronic properties}

In order to understand the binding process, we further examine the interaction between cobalt and $\mathrm{CO}_{2}$ electronic states using molecular orbitals. Fig. 6 shows the molecular orbital representation of the HOMO and HOMO -1 of both $[\mathrm{Co}(\text { salen })]^{-}$and $[\mathrm{Co}($ salen $)-$

Table 1 Structural parameters of bound and unbound $\left[\mathrm{Co}(\text { salen) }]^{-}\right.$and $\mathrm{CO}_{2}$

\begin{tabular}{|c|c|c|}
\hline Parameter & Unbound $[\mathrm{Co}(\text { salen })]^{-}$and $\mathrm{CO}_{2}$ & Bound $\left[\mathrm{Co}(\text { salen })-\mathrm{CO}_{2}\right]^{-}$ \\
\hline Co-N1 bond length $(\AA)$ & 1.796 & 1.826 \\
\hline Co-N2 bond length $(\AA)$ & 1.795 & 1.830 \\
\hline Co-O1 bond length $(\AA)$ & 1.888 & 1.892 \\
\hline Co-O2 bond length $(\AA)$ & 1.889 & 1.891 \\
\hline Co-C bond length $(\AA)$ & - & 2.189 \\
\hline $\mathrm{O}-\mathrm{C}-\mathrm{O}$ bond angle (deg) & 180 & 143.5 \\
\hline $\mathrm{CO}_{2}$ partial charge & $+0.125 e$ & $-0.430 e$ \\
\hline Co partial charge & $+0.079 e$ & $+0.154 e$ \\
\hline
\end{tabular}




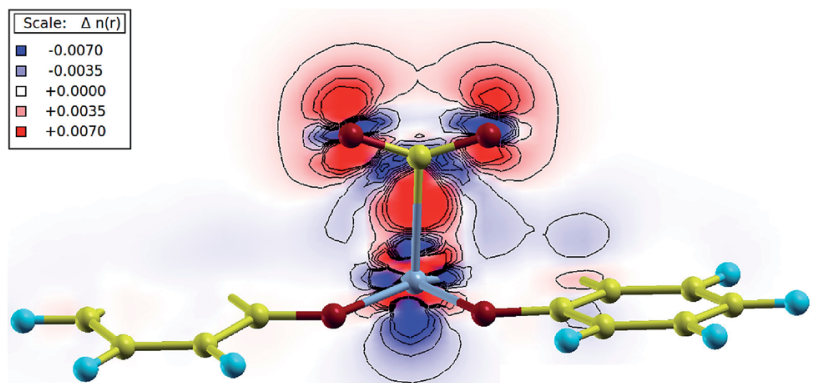

Fig. 5 Charge density difference of the bound $\left[\mathrm{Co}\left(\text { salen) }-\mathrm{CO}_{2}\right]^{-}\right.$and its constituents. The blue color represents the electron deficit regions, while the red color represents regions of excess electron. An isovalue of 0.007 is used to create this plot.

$\left.\mathrm{CO}_{2}\right]^{-}$adducts. From the figure, a bonding molecular orbital is observed in HOMO - 1 of the latter. This is also consistent with Fig. 5 , where charges accumulate between cobalt and carbon atoms to form a $\sigma$ bond. Furthermore, the total density of states shown in Fig. 7 are the same for both spin polarizations. This indicates that the adduct is diamagnetic. Thus, our structure has no net magnetization and the binding of $\mathrm{CO}_{2}$ is mainly due the orbital and electrostatic interactions with Co.

We analyze this orbital overlap by projecting the total density of states onto the atomic orbitals (PDOS). The vertical line on Fig. 7 marks the HOMO -1 state. The PDOS data showed that $\operatorname{Co~}_{z^{2}}, \mathrm{Op}_{z}$, and C $\mathrm{p}_{z}$ have significant contribution to this state. The square modulus of the overlap matrix of the HOMO - 1 orbital with these orbitals are $0.567,0.119$, and 0.018 , respectively. The $\mathrm{Op}_{z}$ and $\mathrm{C} \mathrm{p}_{z}$ orbitals primarily constitute the $\mathrm{CO}_{2} \pi^{*}$ orbital. ${ }^{30}$ Thus, the formation of the $\eta^{1}-\mathrm{CO}_{2} \sigma$ bond is mainly due to the back-donation of electrons from the $\operatorname{Co~}_{z^{2}}$ orbital to the $\mathrm{CO}_{2} \pi^{*}$, typical for compounds which have low-lying empty $\pi^{*}$ LUMO. $^{31}$ As shown in Fig. 8, the LUMO of $\mathrm{CO}_{2}$ coincides well with the Fermi level of $[\mathrm{Co}(\mathrm{salen})]^{-}$. This orbital alignment explains the ease of back-donation and charge transfer. The stabilization brought by the back-bonding and partial charge transfer is due to the lowering of the HOMO - 1 level (HOMO 1 stabilization energy) by $0.621 \mathrm{eV}$ and a corresponding Co-C bond energy of $19.63 \mathrm{~kJ} \mathrm{~mol}^{-1}$.

A way to explain why the $\mathrm{CO}_{2}$ molecule forms a stable bond with the anionic $[\mathrm{Co}(\text { salen })]^{-}$, and not with the neutral $\mathrm{Co}$ (salen) complex, is by analyzing their respective electronic

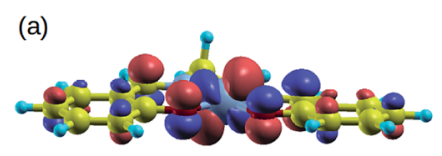

HOMO

(b)

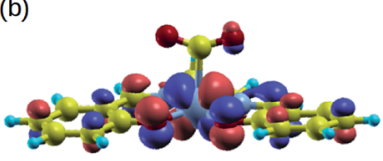

HOMO
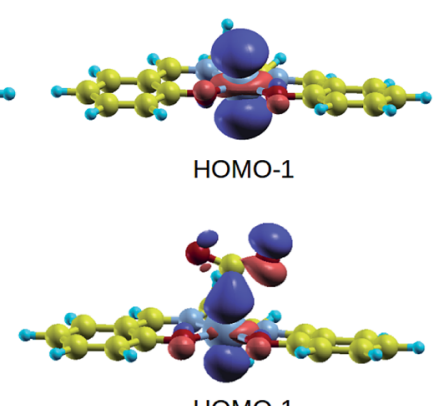

HOMO-1
Fig. $6 \mathrm{HOMO}$ and $\mathrm{HOMO}-1$ of (a) [Co(salen)] $]^{-}$and (b) [Co(salen)$\left.\mathrm{CO}_{2}\right]^{-}$complex. Bonding $\mathrm{MO}$ is observed in $\mathrm{HOMO}-1$.

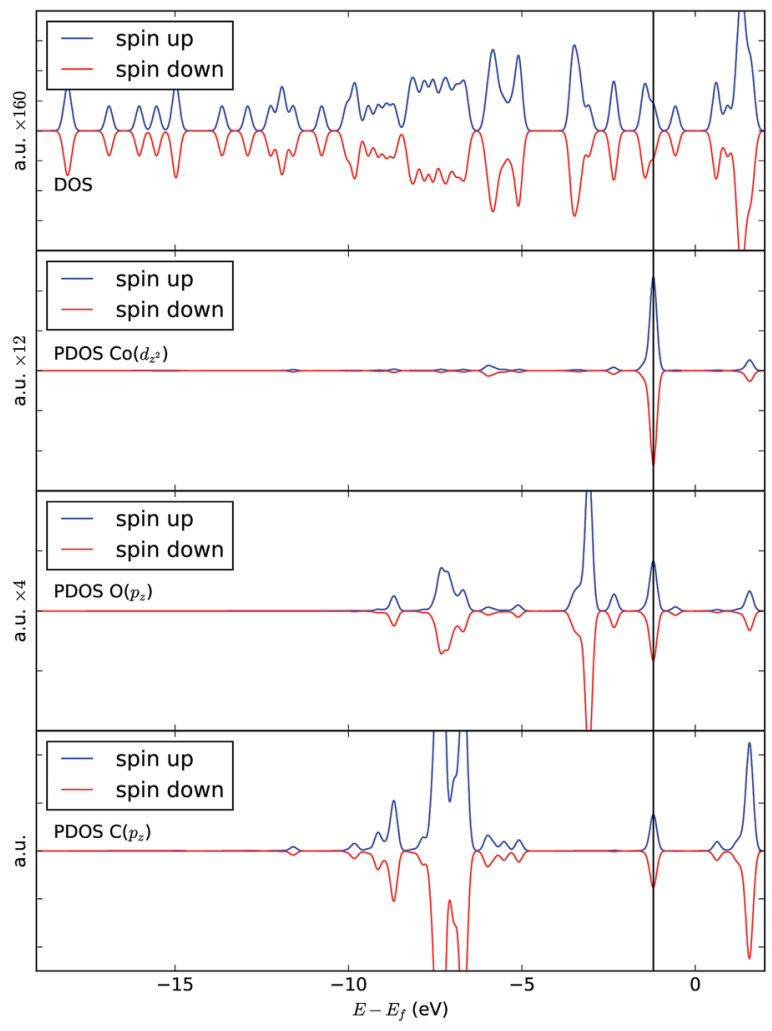

Fig. 7 Top to bottom: total density of states (DOS) of [Co(salen)$\left.\mathrm{CO}_{2}\right]^{-}$, and projected density of states (PDOS) onto $\mathrm{Co} \mathrm{d}_{z^{2}}, \mathrm{Cp}_{z}$ and $\mathrm{O}$ $\mathrm{p}_{z}$ orbitals. The black line marks the $\mathrm{HOMO}-1$ state. Significant contributions to this state are from $\mathrm{Co} \mathrm{d}_{z^{2}}, C \mathrm{p}_{z}$ and $O \mathrm{p}_{z}$ orbitals.

structures before carbon capture. The spin-polarized density of states of both $\mathrm{Co}\left(\right.$ salen) and $[\mathrm{Co}(\text { salen })]^{-}$complexes are shown in Fig. 9. For the neutral $\mathrm{Co}($ salen) complex, the cobalt center has a +2 state with an unpaired electron $\left(\mathrm{d}^{7}, S=0\right)$, and a Fermi energy of $-3.325 \mathrm{eV}$. The local density of Co d states is polarized near the Fermi level, and a spin minority state exists in the midgap region. Upon the initial reduction of $\mathrm{Co}$ (salen) to $[\mathrm{Co}(\text { salen })]^{-}$, the $\mathrm{Co}(\mathrm{II})$ atom is reduced to $\mathrm{Co}(\mathrm{I})$ and the complex becomes non-ferromagnetic as the density of states for both spins are the same $(S=1)$. Here, the d states of the $[\mathrm{Co}(\text { salen })]^{-}$ complex comprise most of HOMO and HOMO - 1. Furthermore, the Fermi energy for the anionic complex increases to $-1.0025 \mathrm{eV}$, allowing the frontier orbitals to have a good overlap with the $\pi^{*}$ LUMO of the $\mathrm{CO}_{2}$ molecule. The additional electron also contributes to the electron-electron repulsion, decreasing the effective nuclear charge experienced by the valence electrons, which explains the increase in Fermi energy. Hence, the additional electron in the anionic $[\mathrm{Co}(\mathrm{salen})]^{-}$facilitates $\mathrm{CO}_{2}$ capture by bringing the frontier orbitals closer to the LUMO of the $\mathrm{CO}_{2}$ molecule.

\section{Nucleophilic properties of phenyl substituted [Co(salen)] ${ }^{-}$}

Manipulating the nucleophilicity of the cobalt center gives rise to the possibility of tuning the chemisorption strength of $\mathrm{CO}_{2}$ to 


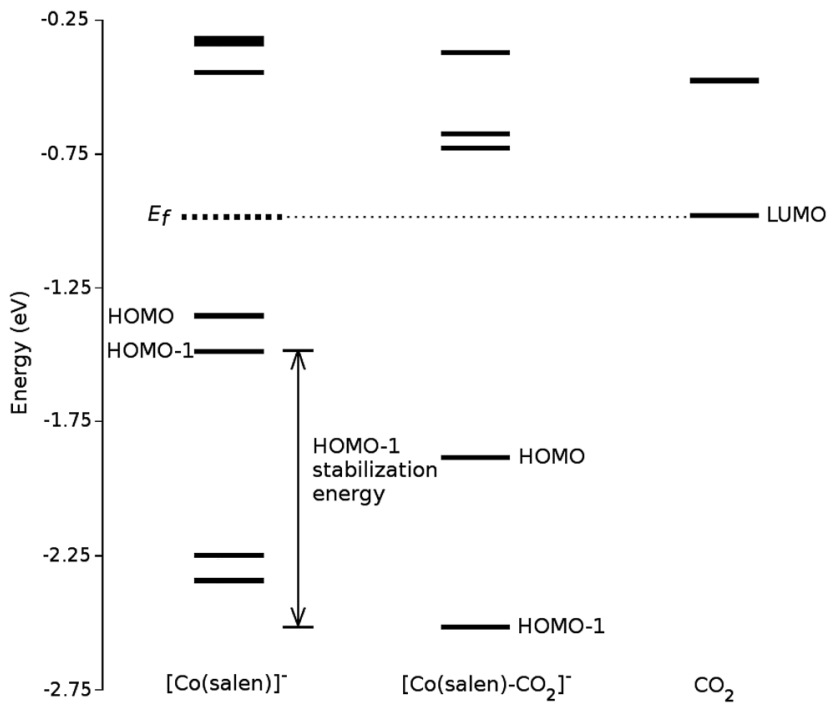

Fig. 8 Molecular orbital diagram of $\left[\mathrm{Co}(\text { salen) }]^{-},\left[\mathrm{Co} \text { (salen) }-\mathrm{CO}_{2}\right]^{-}\right.$, and $\mathrm{CO}_{2}$. The figure shows the alignment of $\mathrm{CO}_{2} \mathrm{LUMO}$ with the Fermi energy of [Co(salen) $]^{-}$, explaining the possibility of back-donation and charge transfer.

$[\mathrm{Co}(\text { salen })]^{-}$by controlling the electron density on the cobalt center. Because the salen ligand is coordinated to the cobalt center with its imine nitrogen and phenolic oxygen, activating
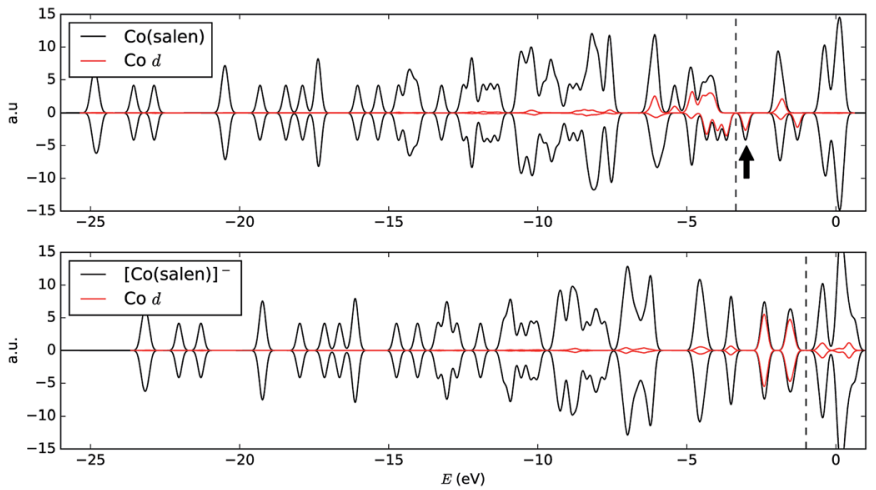

Fig. 9 Electronic density of states of (top) Co(salen) and (bottom) $\left[\mathrm{Co}(\text { salen) }]^{-}\right.$. The Fermi energy is indicated with a dashed line calculated directly from self-consistent field calculation. The Fermi energy increased from $-3.325 \mathrm{eV}$ to $-1.0025 \mathrm{eV}$ after the reduction of $\mathrm{Co}\left(\right.$ salen) to $\left[\mathrm{Co}(\text { salen) }]^{-}\right.$complex, allowing the frontier orbitals to have good overlap with the $\pi^{*}$ LUMO of the $\mathrm{CO}_{2}$ molecule. Local density of $\mathrm{Co} d$ states are shown in red curve. The black arrow points to the polarized $d$ state in the midgap region. or deactivating the conjugated phenyl ring with electron donating or withdrawing groups will affect the electron density on these atoms and on cobalt. Thus, the nucleophilicity of cobalt, a measure of its extent to donate electrons to an electrophile, will be affected by the change in its electron density.

We investigate the changes in nucleophilic properties of $[\mathrm{Co}(\text { salen })]^{-}$by substituting $-\mathrm{NO}_{2}$ and $-\mathrm{OH}$ groups as electron withdrawing and donating groups, respectively, on the phenyl rings. Two substitution sites, R1 and R2, were considered, as shown in Fig. 2. These sites were chosen to account for both paraand meta-substitution of the phenyl ring with respect to the phenolic oxygen. Table 2 shows the HOMO -1 stabilization energy, bond energy, Co-C distance, and charge density on cobalt atom for both unsubstituted and substituted $[\mathrm{Co}(\text { salen })]^{-}$. Fig. 10 shows the relaxed structure of phenyl-substituted [Co(salen)$\left.\mathrm{CO}_{2}\right]^{-}$. On R1, substituting $-\mathrm{NO}_{2}$ significantly weakens the bond as shown by a decrease in bond and HOMO - 1 stabilization energies, while substituting - $\mathrm{OH}$ has little effect on these properties. The weakening is also accompanied by an increase in Co$\mathrm{C}$ bond length and charge density on cobalt. On the other hand, substituting $\mathrm{R} 2$ with $-\mathrm{NO}_{2}$ has similar weakening effect on $\mathrm{R} 1$ as no $\mathrm{Co}-\mathrm{C}$ bond is formed. However, the decreased $\mathrm{Co}-\mathrm{C}$ bond distance upon substituting - $\mathrm{OH}$ on $\mathrm{R} 2$ signifies an increased bond strength and HOMO - 1 stabilization energy.

In order to explain these trends, we propose a mechanism of charge delocalization involving the electron withdrawing and donating groups on the phenyl rings and the cobalt center using its resonance structures. Fig. 11(a) shows how the $-\mathrm{NO}_{2}$ group on R1 withdraws electrons from the phenolic oxygen, decreasing the density of electrons on the oxygen atom that is coordinated to the cobalt center. Hence, we see an increased positive charge density as electrons on the cobalt center are withdrawn, which decreases its nucleophilicity. This weakens the carbon fixing capacity of cobalt as less electrons are now available for back-bonding. Substituting $-\mathrm{NO}_{2}$ on $\mathrm{R} 2$ has a similar effect as electrons are withdrawn from the imine nitrogen as shown in Fig. 12(a). The withdrawal of electrons leaves nitrogen with an incomplete valence shell, thereby decreasing the density of electrons that is coordinated to the cobalt center. The decrease in electron density causes the cobalt atom to be less polarizable, making it a "hard" Lewis base which does not form a strong bond with a "soft" Lewis acid such as carbon dioxide. ${ }^{32}$

In Fig. 11(b), on the other hand, the electron donating effect of the - $\mathrm{OH}$ group on R1 is only confined within the phenyl ring and does not affect the charge density of the phenolic oxygen as

Table 2 Nucleophilic properties of substituted [Co(salen) $\left.-\mathrm{CO}_{2}\right]^{-}$on R1 and R2

\begin{tabular}{|c|c|c|c|c|c|}
\hline & Unsubstituted & $-\mathrm{NO}_{2}$ & $-\mathrm{OH}$ & $-\mathrm{NO}_{2}$ & $-\mathrm{OH}$ \\
\hline Bond energy $\left(\mathrm{kJ} \mathrm{mol}^{-1}\right)$ & 19.63 & 2.23 & 18.32 & 4.06 & 23.48 \\
\hline Co-C bond distance $(\AA)$ & 2.189 & 2.299 & 2.207 & - & 2.166 \\
\hline Charge density on cobalt $\left(\times 10^{-3}\right.$ bohr $\left.^{-3}\right)$ & +0.725 & +0.809 & +0.728 & +1.268 & +0.565 \\
\hline
\end{tabular}


(a)

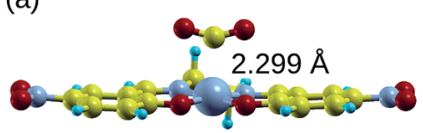

(c)

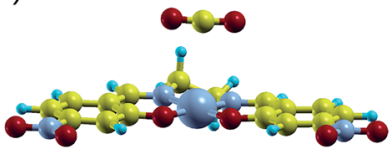

(b)

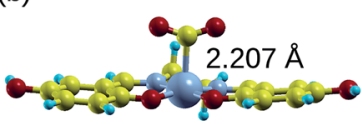

(d)

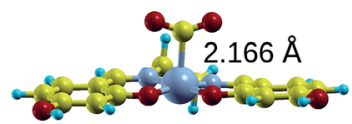

Fig. 10 Relaxed structure of $\left[\mathrm{Co}\left(\text { salen) }-\mathrm{CO}_{2}\right]^{-}\right.$with the phenyl rings substituted with $-\mathrm{NO}_{2}$ and $-\mathrm{OH}$ on R1 ( $a$ and b) and R2 (c and d). Also shown are the $\mathrm{CO}-\mathrm{C}$ bond lengths. $\mathrm{NO}_{2}$-substituted [Co(salen)$\left.\mathrm{CO}_{2}\right]^{-}$have a longer $\mathrm{Co}-\mathrm{C}$ bond length, signifying weaker chemisorption. On the other hand, a $-\mathrm{OH}$ group substituted on $\mathrm{R} 2$ leads to a shorter $\mathrm{Co}-\mathrm{C}$ bond length, while it has less prominent effect on R1.
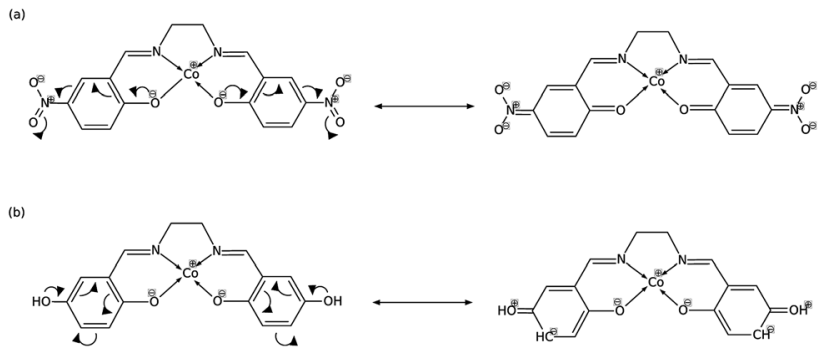

Fig. 11 (a) Substitution on $\mathrm{R} 1$ with $-\mathrm{NO}_{2}$ decreases electron density on cobalt, while (b) substituting with $-\mathrm{OH}$ has no significant effect.

the latter already has full valency. Thus, electron donating groups on R1 have little effect on the nucleophilicity of cobalt. For the OH-substituted phenyl ring in Fig. 12(b), the established resonance structure enables the increased electron density on imine nitrogen. This electron delocalization increases the available electrons coordinated to cobalt so that the positive charge density on cobalt decreases, making it more nucleophilic. The increased nucleophilicity on cobalt forms a stronger $\mathrm{Co}-\mathrm{C}$ bond and leads to an increase in the HOMO - 1 stabilization energy.

Therefore, the carbon fixing capacity of $[\mathrm{Co}(\text { salen })]^{-}$can easily be controlled by substituting electron withdrawing and donating groups on the appropriate locations. Electron donating groups para to the imine group strengthen the $\mathrm{Co}-\mathrm{C}$ bond, while electron withdrawing groups in general weaken it.

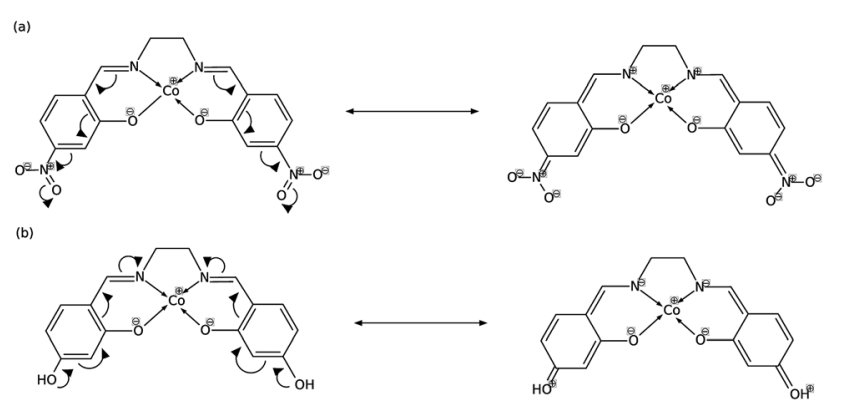

Fig. 12 (a) Substitution on $\mathrm{R} 2$ with $-\mathrm{NO}_{2}$ decreases electron density on cobalt, while (b) substituting with $-\mathrm{OH}$ increases it.
Similarly, functional groups which have similar effect as either $-\mathrm{NO}_{2}$ and $-\mathrm{OH}$ can be substituted in order to achieve the desired Co-C bond strength. These phenyl substitutions allow one to tune the carbon fixing capacity of $[\mathrm{Co}(\mathrm{salen})]^{-}$while improving its selectivity and specificity as a homogeneous catalyst for the electrochemical reduction of $\mathrm{CO}_{2}$.

\section{Conclusions}

We presented a theoretical model that predicts carbon dioxide capture on $\mathrm{Co}($ salen) after reducing this organometallic catalyst to $[\mathrm{Co}(\text { salen })]^{-}$. The bonding favors the formation of an $\eta^{1}-\mathrm{C}$ mode where a $\sigma$ bond is formed by the overlap of the $\operatorname{Co~}_{z^{2}}$ and $\mathrm{CO}_{2} \pi^{*}$ orbitals. Additionally, this bonding is accompanied by a partial charge transfer due to the back-donation of electrons to the low-lying LUMO of $\mathrm{CO}_{2}$, since it lies very close to the Fermi energy of $[\mathrm{Co}(\text { salen })]^{-}$. The interaction of $\mathrm{CO}_{2}$ with the complex lowers the energy of the HOMO -1 orbital by approximately $0.621 \mathrm{eV}$. Altering the charge density around the phenyl rings of the catalyst affects the nucleophilicity of the cobalt center so that electron withdrawing groups weaken the $\mathrm{Co}-\mathrm{C}$ bond strength. Meanwhile, electron donating groups in the para position with respect to the imine nitrogen increases the nucleophilicity of the cobalt center. The theoretical treatment done here can be refined further in future work to account for solvation effects by using a polarizable continuum model, employing hybrid functionals, and applying van der Waals corrections to the dispersion interaction. Still, the results of this study provide a sound basis for the experimental investigation of the electrochemical reduction of $\mathrm{CO}_{2}$ by $\mathrm{Co}$ (salen) and other similar organometallic catalysts.

\section{Conflicts of interest}

There are no conflicts to declare.

\section{Acknowledgements}

MRC acknowledges the support of the DOST-SEI through its ASTHRDP Scholarship. This work is supported by the UP System Enhanced Creative Work and Research Grant ECWRG 2018-1009.

\section{References}

1 J. Qiao, Y. Liu, F. Hong and J. Zhang, Chem. Soc. Rev., 2014, 43, 631-675.

2 B. Khezri, A. C. Fisher and M. Pumera, J. Mater. Chem. A, 2017, 5, 8230-8246.

3 Y. Hori, Electrochemical $\mathrm{CO}_{2}$ reduction on metal electrodes, Springer, New York, 2008, vol. 42, pp. 89-189.

4 Y. Zhao, C. Wang and G. G. Wallace, J. Mater. Chem. A, 2016, 4, 10710-10718.

5 A. Eilert, F. S. Roberts, D. Friebel and A. Nilsson, J. Phys. Chem. Lett., 2016, 7, 146-1470.

6 R. Francke, B. Schille and M. Roemelt, Chem. Rev., 2018, 4631-4701. 
7 M. Aresta, C. F. Nobile, V. G. Albano, E. Forni and M. Manassero, J. Chem. Soc., Chem. Commun., 1975, 636-637. 8 K. Pandey, Coord. Chem. Rev., 1995, 140, 37-114.

9 J. Mascetti, Carbon dioxide as chemical feedstock, Wiley-VCH \& Co., Weinheim, 2010, ch. 4, pp. 55-88.

10 T. Yoshida, K. Kamato, M. Tsukamoto, T. Iida, D. Schlettwein, D. Wohrle and M. Kaneko, J. Electrochem. Soc., 1995, 385, 209-225.

11 N. Sonoyama, M. Kirii and T. Sakata, Electrochem. Commun., 1999, 1, 213-216.

12 M. Beley, J. P. Collin, R. Ruppert and J. P. Sauvage, J. Am. Chem. Soc., 1986, 108, 7461-7467.

13 J. Shen, M. J. Kolb, A. J. Gottle and M. T. M. Koper, J. Phys. Chem. C, 2016, 120, 15714-15721.

14 I. Nielsen and K. Leung, J. Phys. Chem. A, 2010, 114, 1016610173.

15 K. Leung, I. Nielsen, N. Sai, C. Medforth and J. A. Shelnutt, J. Phys. Chem. A, 2010, 114, 10174-10184.

16 S. Gambarotta, F. Arena, C. Floriani and P. F. Zanazzi, J. Am. Chem. Soc., 1982, 104, 5082-5092.

17 S. Singh, B. Phukan, C. Mukherjee and A. Verma, RSC Adv., 2015, 5, 3581-3589.

18 J. P. Perdew, K. Burke and M. Ernzerhof, Phys. Rev. Lett., 1996, 77, 3865-3868.

19 W.-L. Yim and T. Klüner, J. Comput. Chem., 2008, 29, 13061315.
20 E. Maggio, P. Liu, M. J. van Setten and G. Kresse, J. Chem. Theory Comput., 2017, 13, 635-648.

21 C. Massobrio and E. Ruiz, Monatsh. Chem., 2003, 134, 317326.

22 G. Makov and M. C. Payne, Phys. Rev. B: Condens. Matter Mater. Phys., 1995, 51, 4014-4022.

23 G. Henkelman, J. Chem. Phys., 2000, 113, 9901.

24 P. Giannozzi, S. Baroni, N. Bonini, et al., J. Phys.: Condens. Matter, 2009, 21, 395502.

25 A. Kokalj, J. Mol. Graphics Modell., 1999, 17, 176-179.

26 W. Tang, E. Sanville and G. Henkelman, J. Phys.: Condens. Matter, 2009, 21, 084204.

27 M. Rosi, A. Sgamellotti, F. Tarantelli and C. Floriani, J. Organomet. Chem., 1987, 332, 153-164.

28 S. Sakaki, K. Kitaura and K. Morokuma, Inorg. Chem., 1982, 21, 760-765.

29 R. Caballol, E. S. Marcos and J.-C. Barthelat, J. Phys. Chem., 1987, 91, 1328-1333.

30 A. Dedieu, C. Bo and F. Ingold, Metal-Ligand Interactions: From Atoms, to Clusters, to Surfaces, Kluwer Academic Publishers, Dordrecht, The Netherlands, 2007, p. 179.

31 R. Stadler and K. W. Jacobsen, Phys. Rev. B: Condens. Matter Mater. Phys., 2006, 74, 164105.

32 R. G. Pearson, J. Chem. Educ., 1968, 45, 176-179. 